\title{
NOVA UNIDADE LITOESTRATIGRÁFICA CENOZÓICA DA BACIA DE TAUBATÉ, SP: FORMAÇÃO PINDAMONHANGABA
}

\author{
C.Riccomini ${ }^{1,2}$ \\ A.M.Coimbra ${ }^{1,2}$ \\ K.Suguio ${ }^{1,2}$ \\ P.Mihály ${ }^{2,3}$ \\ E.C.Maturana ${ }^{2,3}$
}

\section{INTRODUÇÃO}

Os depósitos sedimentares continentais terciários da Bacia de Taubaté, integrantes do Rift Continental do Sudeste do Brasil, constituem uma seqüência basal, Grupo Taubaté, capeada por uma unidade mais jovem, a Formação Pindamonhangaba (RICCOMINI, 1989), objeto de caracterização litoestratigráfica formal no presente artigo.

O Grupo Taubaté, de idade paleogênica, corresponde ao preenchimento vulcano-sedimentar sintectônico do rift, compreendendo um sistema de leques aluviais associados à planície aluvial de rios entrelaçados (braided), basal e lateral na bacia (Formação Resende), um sistema playa-lake (Formação Tremembé), um sistema fluvial meandrante (Formação São Paulo), além de rochas efusivas ultrabásicas (Basanito Casa de Pedra), estas presentes na área de Volta Redonda, RJ (RICCOMINI, 1989).

A Formação Pindamonhangaba corresponde aos depósitos de sistema fluvial meandrante, bem desenvolvidos na porção central da Bacia de Taubaté (região de CaçapavaPindamonhangaba), em faixa situada ao sul do Rio Paraíba do Sul (Fig. 1). É separável do

\footnotetext{
${ }_{1}$ Departamento de Paleontologia e Estratigrafia, Instituto de Geociências/USP, São Paulo.

2 Bolsista do CNPq.

${ }^{3}$ Graduação, Instituto de Geociências/USP, São Paulo.
} 
Grupo Taubaté pela existência de importante discordância angular, bem marcada sobretudo quando desenvolvida sobre os sedimentos pelíticos da Formação Tremembé, já que estes encontram-se dobrados.

Diferentemente dos depósitos da Formação São Paulo, na Formação Pindamonhangaba não são encontradas intercalações de lamitos da Formação Resende, o que indicaria condições de maior calmaria tectônica.

O principal corpo de sedimentos da Formação Pindamonhangaba vinha sendo designado por Formação Caçapava (CARNEIRO et al., 1976), esta incluindo ainda os depósitos do sistema de leques aluviais associados à planície de rios entrelaçados, aos quais RICCOMINI (1989) estendeu a denominação Formação Resende. Assim, o termo Formação Caçapava encontra-se prejudicado, por abranger depósitos litologicamente distintos, separados por discordância regional. Some-se a isto o fato de haver na literatura geológica o Granito de Caçapava (TEIXEIRA, 1937), que teria prioridade no emprego do termo.

\section{EXTENSÃO EM ÁREA E ESPESSURA}

A discordância basal da Formação Pindamonhangaba, conquanto localmente perturbada por deformaçôes tectônicas, constitui-se numa superfície bem nivelada na cota 550$560 \mathrm{~m}$, com leve caimento rumo à borda norte da bacia, de sorte que, regionalmente, pode-se considerá-la como um plano de orientação ENE com tênue mergulho para o quadrante noroeste. Encontra-se bem exposta no km 333 (marco quilométrico) da Estrada de Ferro Central do Brasil (EFCB), onde já havia sido descrita por ALMEIDA (1955), embora considerada posteriormente como de caráter local (HASUI \& PONÇANO, 1978). Entretanto, ela pode ser facilmente verificada nos perfis de sondagens do Conselho Nacional do Petróleo, bem como em superfície, estando bem exposta nos seguintes locais: entroncamento da Rodovia Presidente Dutra (BR-116) com a estrada Caçapava-Caçapava Velha; Rodovia SP123, em corte do lado direito, rumo a Quiririm, cerca de 1,4-1,5 km da Rodovia Presidente Dutra; aproximadamente $2,3 \mathrm{~km}$ da antiga fundição da Willys Overland, Taubaté, seguindo pela via férrea, na pequena escarpa para a várzea do Rio Paraíba do Sul, entre outros. Dessa forma, é uma superfície de extensão regional.

Além dessa discordância basal, bem demarcada por um nível conglomerático, outra característica conspícua associada à Formação Pindamonhagaba são as extensas "superfícies aplainadas" que nivelam o seu topo, devidas sem dúvida à persistência lateral e 
planaridade dos seus depósitos constituintes. Os platôs da região de Caçapava, Quiririm (notadamente onde se situa a Fábrica da Volkswagem), Taubaté e Pindamonhangaba, nivelados em 580-585 m, são remanescentes dessa superfície, hoje em processo de entalhamento. Sem dúvida a sua gênese é antes devida à deposição do que à erosão, à semelhança do que FÚLFARO \& SUGUIO (1968) admitiram para a origem da feição de topo da Formação Rio Claro.

Tomando-se como referência os níveis de topo e de base acima descritos, pode-se estimar em cerca de 30 metros a espessura máxima para a formação.

Outros depósitos, especialmente os situados ao longo da Rodovia Presidente Dutra, logo na entrada para São José dos Campos e no km 149,5 (arredores da indústria Bundy), apresentam características sedimentares e geomorfológicas semelhantes aos da região de Caçapava-Pindamonhangaba, podendo, ainda que preliminarmente, serem também referidos à Formação Pindamonhangaba.

\section{FÁCIES E SISTEMA DEPOSICIONAL}

Nos depósitos da Formação Pindamonhangaba são reconhecidas sete litofácies principais.

a - fácies de conglomerados, com espessura decimétrica, com seixos (ocasionalmente calhaus e matacões) bem arredondados de quartzito e quartzo, em matriz essencialmente arenosa grossa mal selecionada; ocupam posição basal no sistema e representariam a fase de instalação fluvial, inicialmente em condições de energia alta a moderada;

b - fácies de arenitos argilosos grossos, mal selecionados, localmente níveis conglomeráticos de espessura decimétrica com seixos de quartzo e quartzito, bem arrendondados, apresentando todo o conjunto estratificação cruzada tabular decimétrica e espessura métrica; gradam na base para a fácies a, representando prováveis barras-de-pontal (point bar);

c - fácies de areias médias a finas, argilosas, mal selecionadas, com estratificações cruzadas acanaladas centimétricas a decimétricas; gradam lateralmente para a fácies b, constituindo-se nos depósitos de dunas subaquosas de cristas sinuosas em canal fluvial;

d - fácies de siltitos, ora maciços, ora estratificados ou laminados, apresentando no conjunto espessura métrica; passam, na base, para as areias da fácies c, 
representando depósitos de abandono de canal fluvial e/ou transbordamento;

e - fácies de arenitos conglomeráticos, com abundante matriz argilosa, granodecrescentes para siltitos e argilitos, em camadas de espessura métrica dispostas segundo estratificações sigmoidais métricas, com estruturas tipo climbing ripples na porção distal destas; estes depósitos estariam ligados ao rompimento de diques marginais (crevasse splay), com a brusca colocaçáo de massas consideráveis de sedimentos em águas mais calmas de meandros abandonados (oxbow lakes) ou planície de inundação; a forma desses corpos lembraria a das ondas-de-areia (sand waves), ao passo que as estruturas sigmóides internas representariam o perfil de equilíbrio da massa de sedimentos com a abrupta quebra da energia de transporte;

f - fácies de arenitos de granulação média a grossa, gradando para o topo para sedimentos progressivamente mais finos, até siltitos e argilitos, com estruturas gradacionais normais, rítmicas, estratificaçōes plano-paralelas horizontais de espessura centimétrica a decimétrica e grande persistência lateral, contendo ainda nas porções arenosas de granulação fina estruturas tipo climbing ripples; representariam prováveis depósitos de planície de inundação;

g - lamitos arenosos, contendo ocasionalmente grânulos de quartzo, ocorrem por vezes nas proximidades dos depositos de rompimento de diques marginais e planície de inundaçăo. Como não apresentam geometria peculiar, nem tampouco relações mais claras de contato com estas fácies, sua interpretação genética fica prejudicada.

A associação de fácies é típica de sistema fluvial meandrante. A presença generalizada de caulinita detrítica nos sedimentos da Formação Pindamonhangaba sugere condições climáticas úmidas, em concordância com o ambiente de sedimentação postulado (RICCOMINI, 1989). Entretanto, maiores considerações sobre o paleoclima ficam na dependência dos estudos anatômicos das plantas fósseis presentes na formação.

\section{SEÇÃO-TIPO E SEÇÕES-DE-REFERÊNCIA DA FORMAÇÃO PINDAMONHANGABA}

A designação Pindamonhangaba foi emprestada do município homônimo, onde está situada a seção-tipo dessa unidade litoestratigráfica. Elegeu-se como holoestratótipo dessa formação os afloramentos situados nos arredores do $\mathrm{km} 333$ da $\mathrm{EFCB}$, onde a discordância com as argilas verdes da Formação Tremembé foi originalmente descrita por ALMEIDA (1955). A seção colunar composta, apresentada na Figura 2, é considerada tipo 
desta formação e foi construída a partir das observações no afloramento do km 333 da EFCB e nos cortes vizinhos, na estrada Pindamonhangaba-Tremembé, nas proximidades do entroncamento com a SP-60, local 1, Figura 2. Como hipoestratótipos da formação (seções-dereferência) podem ser relacionados os afloramentos dos kms 120 (fácies de crevasse splay), próximo ao entroncamento com a SP-123 (local 2, Figura 2) e 124,5 (fácies de planície de inundação) da Rodovia Presidente Dutra (local 3, Figura 2), bem como aquele situado cerca de 2,3 km da saída 109 da Rodovia Presidente Dutra (fácies de planície de inundação, local 4, Figura 2), nos arredores de Tabuões.

\section{IDADE E CORRELAÇÕES}

Impressões de folhas e pequenos caules apresentam distribuição generalizada nos sedimentos pelíticos da formação. As investigações já iniciadas nesses materiais vêm demostrando que eles apresentam pouco valor em termos cronológicos, pelo menos ao nível do conhecimento atual, dada a semelhança com formas viventes (F.C. Fittipaldi, informação verbal). A cor dos sedimentos, por sua vez, não parece ser promissora para a ocorrência de

palinomorfos. Assim, a idade dos depósitos só pode ser referida aos eventos tectônicos e às feições geomorfológicas regionais.

A Formação Pindamonhangaba assenta-se em discordância sobre sedimentos oligocênicos (Grupo Taubaté). Por outro lado, a formação é recoberta por sedimentos coluviais e aluviais de idade pleistocênica (RICCOMINI et al., 1989).

A última regressão marinha da região, anterior ao Pleistoceno Superior, foi a responsável pela deposição da Formação Cananéia, de idade Sangamoniana, há cerca de 120.000 anos A.P. (SUGUIO \& MARTIN, 1978). Esta regressão testemunharia rebaixamento global do nível do mar e esfriamento, sendo precedida por transgressão cujo máximo ocorreu há 0,8-1,3 Ma (HAQ et al., 1987), esta provavelmente em condiçōes mais úmidas, compatíveis com a deposição do sistema em questão. Dessa forma, esse intervalo pleistocênico poderia representar a idade mínima da Formação Pindamonhangaba.

Nessa mesma linha de raciocínio e, com base em correlações geomorfológicas ainda precárias, pode ser suposta correlação entre os depósitos da Formação Pindamonhangaba e os sedimentos das formações Rio Claro, no interior, e Pariqüera-Açu, da porção sul paulista, com já aludido por MELO (1990). 


\section{REFERÊNCIAS BIBLIOGRÁFICAS}

ALMEIDA, F.F.M. (1955) As camadas de São Paulo e a tectônica da Serra da Cantareira. Boletim da Sociedade Brasileira de Geologia, 4:23-40.

CARNEIRO, C.D.R.; HASUI, Y.; GIANCURSI, F.D. (1976) Estrutura da Bacia de Taubaté na região de São José dos Campos. In: CONGRESSO BRASILEIRO DE GEOLOGIA, 29, Ouro Preto. Anais. Ouro Preto, SBG. V.4, p. 247-256.

FÚlfaro, V.J. \& SUGUIO, K. (1968) A Formação Rio Claro (Neocenozóico) e seu ambiente de deposição. O IGG, 20:45-60.

HAQ, B.U.; HARDENBOL, J.; VAII, P.R.; WRIGHT, R.C.; STOVER, L.E.; BAUM, G.H.; CHENE, R.J.D.; COLIN, J.P.; IOANNIDES, N.; SARG, J.F.; MORGAN, B.E. (1987) Mesozoic-Cenozoic cycle chart (version 3.1 A).

HASUI, Y. \& PONÇANO, W.L, (1978) Organização estrutural e evolução da Bacia de Taubaté. In: CONGRESSO BRASILEIRO DE GEOLOGIA, 30, Recife, 1978. Anais. Recife, SBG. V.1, p. 368-381.

MELO, M.S. (1990) A Formação Pariqüera-Açu e depósitos relacionados: sedimentação, tectônica e geomorfogênese. São Paulo, 211 p. (Dissertação de Mestrado, Instituto de Geociências/USP).

RICCOMINI, C. (1989) O Rift Continental do Brasil. São Paulo, 256 p. (Tese de Doutorado, Instituto de Geociências/USP).

RICCOMINI, C.; PELOGGIA, A.U.G.; SALONI, J.C.L.; KOHNKE, M.W.; FIGUEIRA, R.M. (1989) Neotectonic activity in the Serra do Mar Rift System (Southeastern Brazil). Journal South American Earth Sciences, 2(2):191-197.

SUGUIO, K. \& MARTIN, L. (1978) Formações quaternárias marinhas do litoral paulista e sul fluminense. In: INTERNATIONAL SYMPOSIUM ON COASTAL EVOLUTION IN THE QUATERNARY, São Paulo, 1978. Special Publication. São Paulo, 
IGUSP/SBG. V.1, p.55. (Special Publication, $\mathrm{n}^{\mathrm{Q}}$ 2)

TEIXEIRA, E. (1937) Cobre no Rio Grande do Sul. Avulso. Serviço de Fomento da Produção Mineral, 22:1-27. 

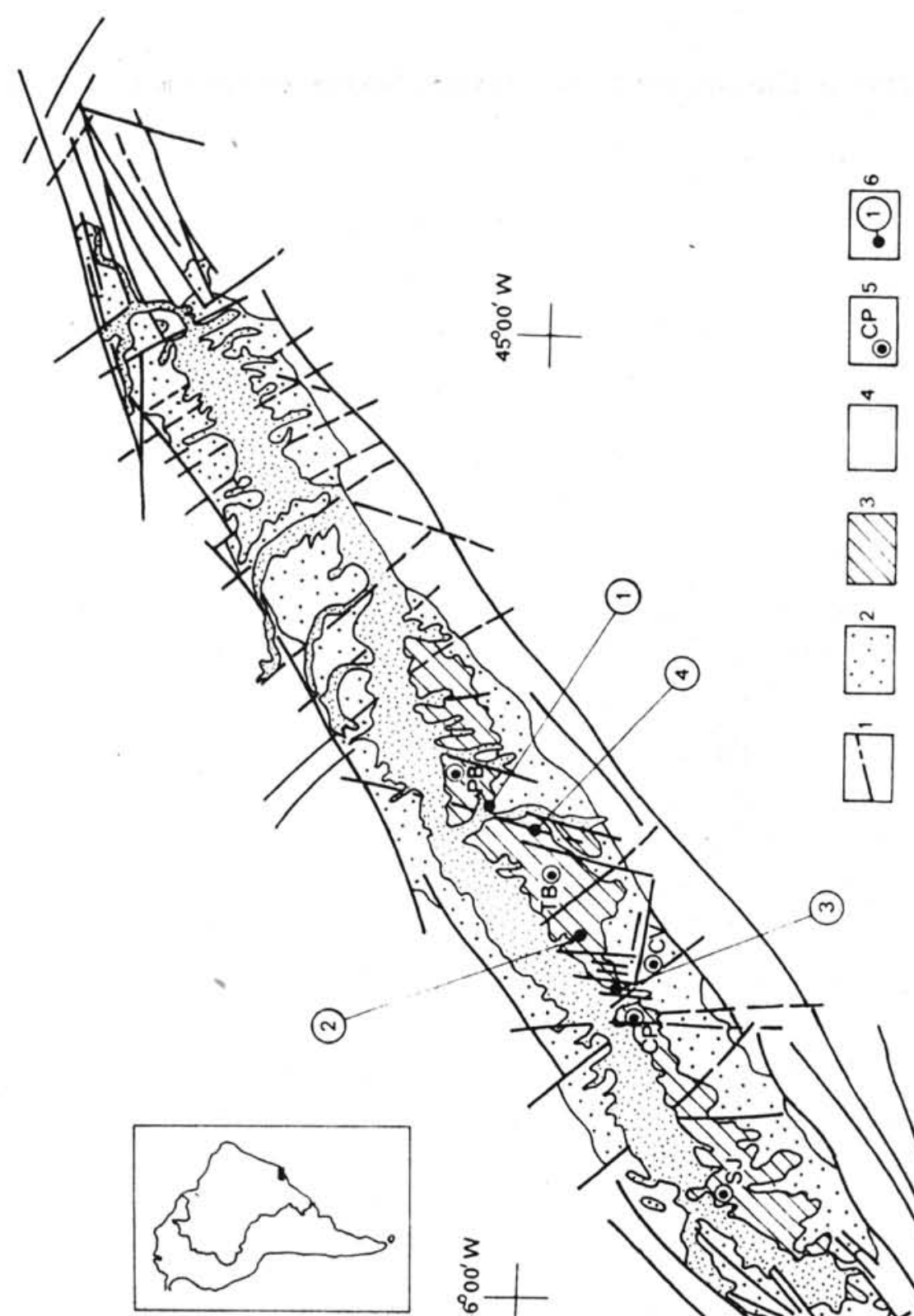

$\odot$
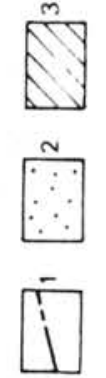

(9)
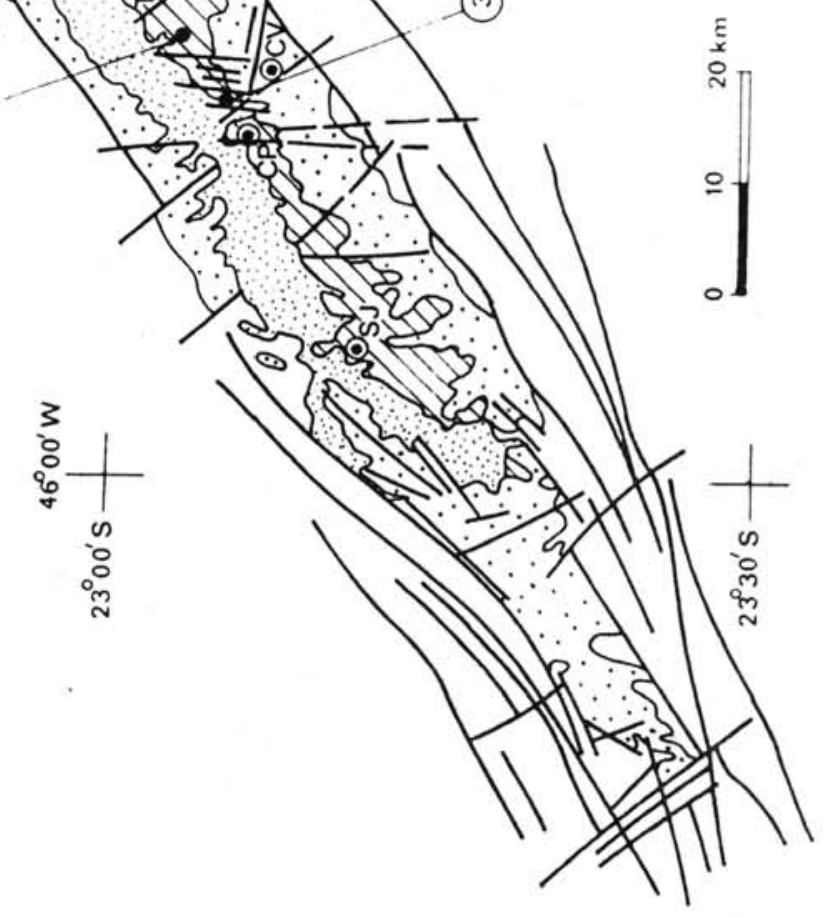

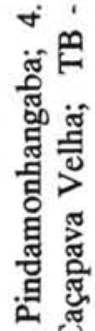

Iี

范

它

ni

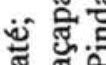

లั

ซ్ '

ㅇํ

总证

슬

गี

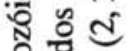

․․

잉

'

需它

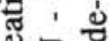

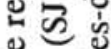

\%

余总

要典

긍

苟急

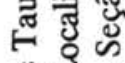

ษ

旁

ㅇํㅁ

. E

흥

喝.

敢瓷

1 \%

ส․ำ

些品 


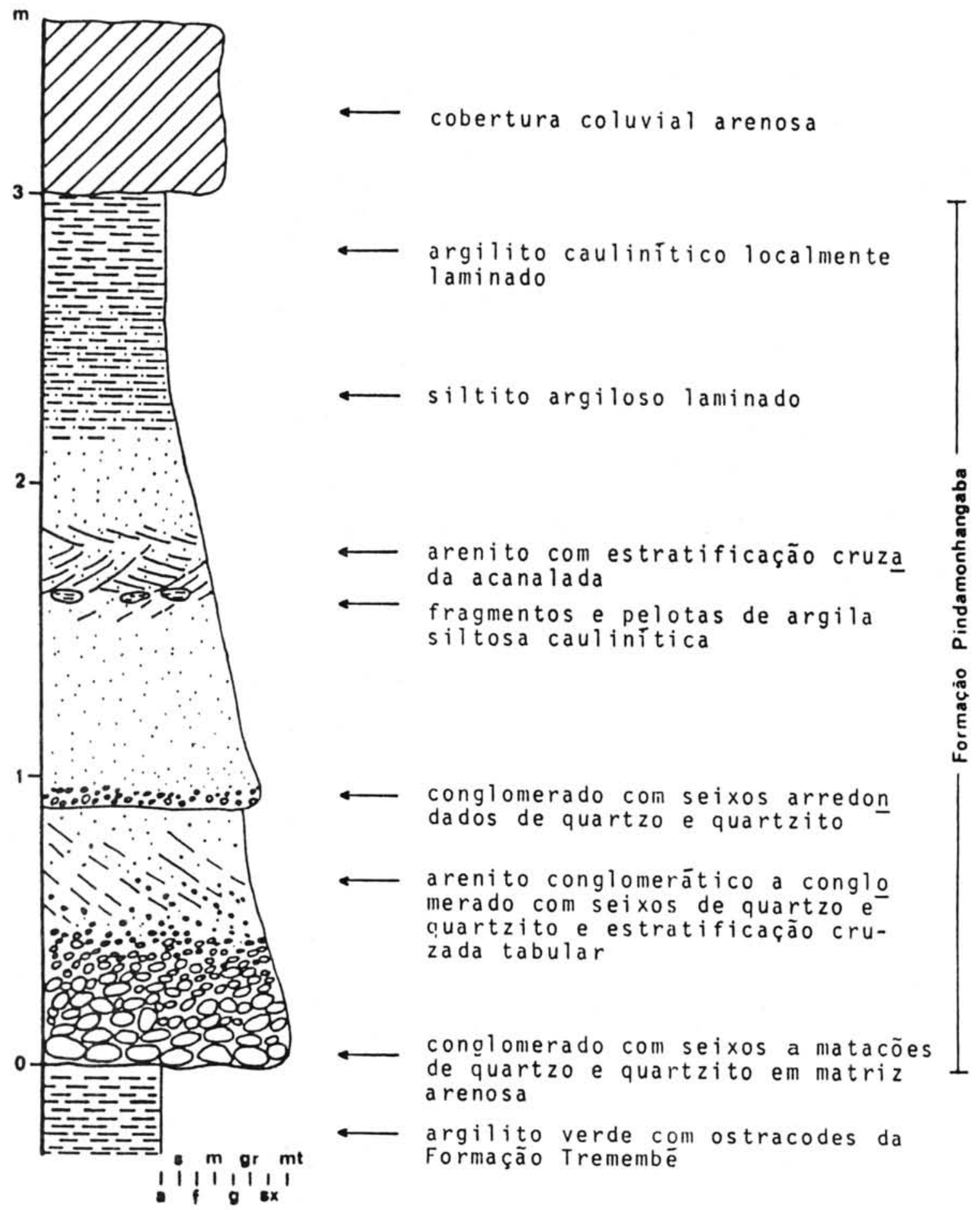

Figura 2 - Seção-tipo da Formação Pindamonhangaba (composta). Coordenadas aproximadas $22^{\circ} 5730^{\prime \prime} \mathrm{S}$ $45^{\circ} 30^{\prime} 10^{\prime \prime} \mathrm{W}$. 